\title{
THE ECONOMIC CHALLENGES IN TIMES OF COVID-19, CIRCULAR LABOR MIGRATION, THE NECESSITY TO SWITCH FROM A LINEAR TO A CIRCULAR ECONOMY AND BUSINESS OPPORTUNITIES
}

\author{
Solomon Pavliashvili, Doctor of Economics, Professor of Georgian Technical University, Tbilisi, \\ Georgia, ORCID ID: https://orcid.org/0000-0002-9006-1039 \\ David Gubeladze, Doctor of Technical Sciences, Professor of Georgian Technical University, Faculty \\ of Agrarian Sciences and Biosystems Engineering, Tbilisi, Georgia, \\ ORCID ID: https://orcid.org/0000-0002-8332-3694
}

DOI: https://doi.org/10.31435/rsglobal_conf/25122020/7303

\begin{abstract}
To move to a circular economy model in the agricultural sector, EU countries have developed a long-term 30-year strategic development plan, which implies the development of important normative acts and investments in the economy - sustainability of agroecosystems, optimal use of natural resources, protection of environment from the pollution, stimulation of reproduction, etc. - for the transition to a closed cycle of agricultural circular economy. Taking into account the specifics of Georgia's agriculture, it is quite possible to share the experiences of EU countries in terms of intensification of agricultural production, increasing efficiency, access to knowledge, application of modern information technologies.
\end{abstract}

Keywords: Circular Economy, Agriculture, Business Opportunities, Effective Management, Reproduction, Economy During the COVID-19 Pandemic.

Introduction. The global pandemic COVID-19 is still spreading rapidly and poses a threat to human health and has the greatest negative impact on the process of food demand and supply. The risks of a food crisis are increasing, especially for poor and vulnerable countries. Closing the borders, quarantines, closed markets and delays in trade in general are particularly affecting countries that are severely affected by the virus and food insecurity.

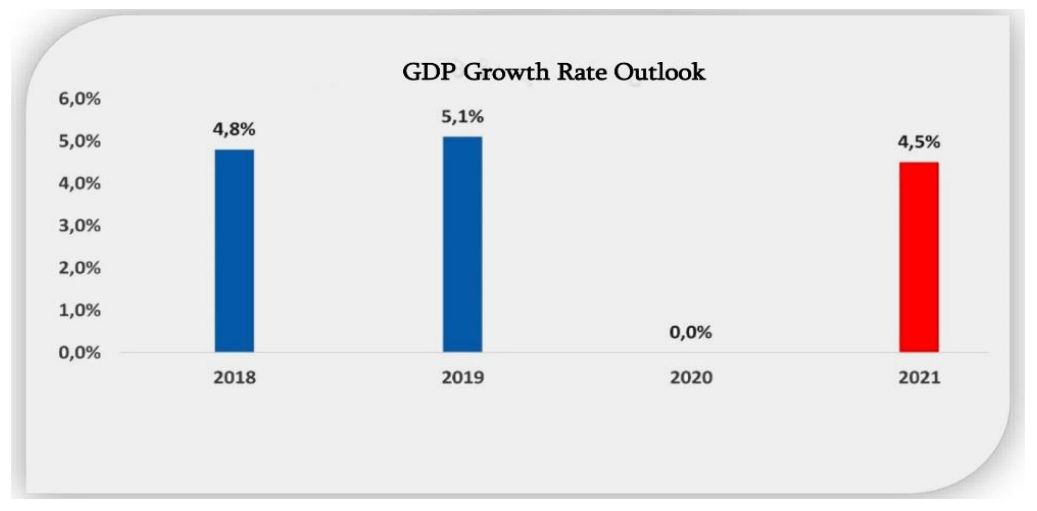

Fig. 1. Georgia's GDP Outlook for 2021

Source: The Asian Development Bank. Asian Development Outlook. April 2020

Even in the most developed countries of the world in the very early period of shift from a linear economy to a circular economy, the effective economic performance of economic entities was influenced by the linear economic approaches, schemes and regulations prevailing between production and consumption: assessment of markets, investment instruments and practices, including financial risks. Today's agriculture is adapted to linear economic models. External factors and existing challenges related to linear business models are not taken into account. It is important to bear in mind that standing on the front line of development and moving to the next step are prerequisite for maintaining sustainability for development. The multifaceted process of globalization is an indicator that shows how the world is developing, making it easier for us to actually define the conditions for adaptation, which requires a high level of public awareness, global thinking and local effective action.

Study Methodology. Circular labor migration for economic effective administration is often promoted as a "Triple Win" proposition, providing benefits to countries of both destination and origin, as well as to the migrants. 
The "win-win-win" argument often claimed for managed circular migration schemes relates to: for migrants;

- responding to labor market needs in receiving countries without issuing permanent residence

- without brain drain, reducing irregular migration, and benefiting from remittances, knowledge, and skills transfers;

- improving socio-economic conditions and qualifications of individual migrants. Once the benefits are in place, it is particularly interesting to understand the scale of the benefits.

It is hard to see how Georgian migrant workers act as significant deal winners in circular migration, considering the limited choice of job opportunities. Based on a detailed analysis of both Georgian and EU labor markets, service sphere and agricultural activities were identified as the primary target occupational groups for inclusion in low-paid circular migration schemes.

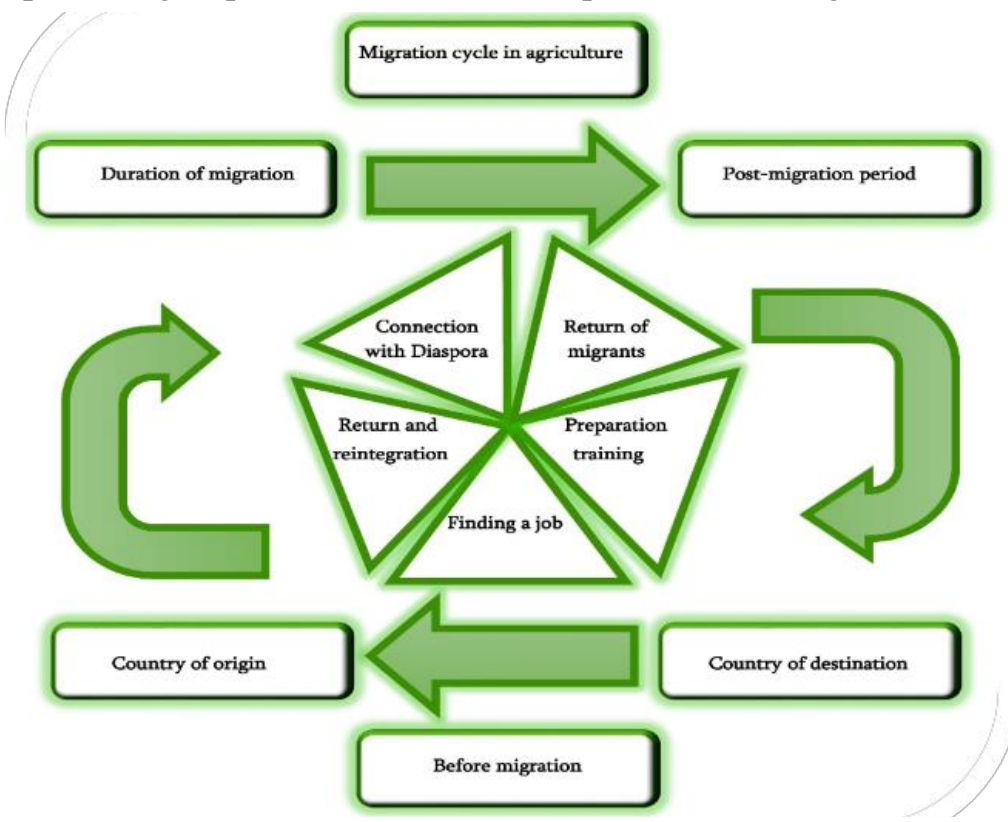

Fig. 2. Circular migration of labor resources

According to the study, the number of employees working in these areas is greater than the number of individuals who are formally qualified for these jobs. In addition, they accumulate considerable work experience and skills, and can be easily retrained to meet the requirements set by European employers. There are also some opportunities for personnel having a diploma for involvement in circular migration. Considering the prioritized target group of migrants, the same study identified the best suited EU destinations for the Georgian labor supply. These countries are Austria, Germany, Belgium, Italy, Slovakia, Slovenia, Hungary, Finland, Sweden, Poland, Malta, and Croatia. It would therefore be important for Georgia to sign bilateral agreements with these countries, making it more likely that the investments sending nations offer for the vocational training of potential migrants is not wasted. The gains of the sending country are very much dependent on the benefits received by the migrants.

The impact of circular migration on the county of origin is rather limited, given the small quotas of legal migration opportunities provided, and the small scale of circular migration programmes, if any, that is unlikely to make a substantial development impact on sending countries facing high unemployment. Georgia cooperates with countries such as Greece, Norway, Sweden, Finland, Lithuania, Spain, Portugal, Estonia, the Czech Republic, Hungary and Ireland within the framework of the bilateral agreement on circular migration. Though, even if all 16 signatories of the Mobility Partnership declaration provide an annual quota for Georgia, the number would be too small to make a significant development impact on the country and will only marginally reduce unemployment. If we take 650 as rough estimate for the quotas given by other signatory countries, similar to France, the total number of annual entries would account to 10,400 . Assuming those estimated 10,400 quotas solely address the unemployed (an unrealistic scenario), only $4.2 \%$ of total unemployed could benefit from circular migration schemes. Thus, this quota would only affect a few thousand illegally working emigrants, without any further unemployment relief. For the receiving countries, circular migration schemes seem to be extremely beneficial, as the destination countries increase their economic production by filling sectoral labor market shortages with "labor without people". 
Empirical studies on circular migration are scarce due to a lack of statistics. This hinders the understanding of the phenomenon and the measurement of the full costs and benefits associated with circular migration deals, which may affect the sending or host countries' capacity to make informed policy decisions. While developing circular migration schemes is a useful undertaking, the labor market relief such schemes may provide for countries of origin would be too small to truly affect an unemployment problem. Addressing high level of unemployment requires policy measures and strategies aimed at developing the economy to create more and better jobs locally. In order to maximize the benefits of circular migration for the sending country, subsequent efforts should also be taken to provide employment and reemployment opportunities for returning migrants. In many instances returned migrants can bring back improved skills and higher qualifications (gained via training and working abroad), that would benefit the local labor market.

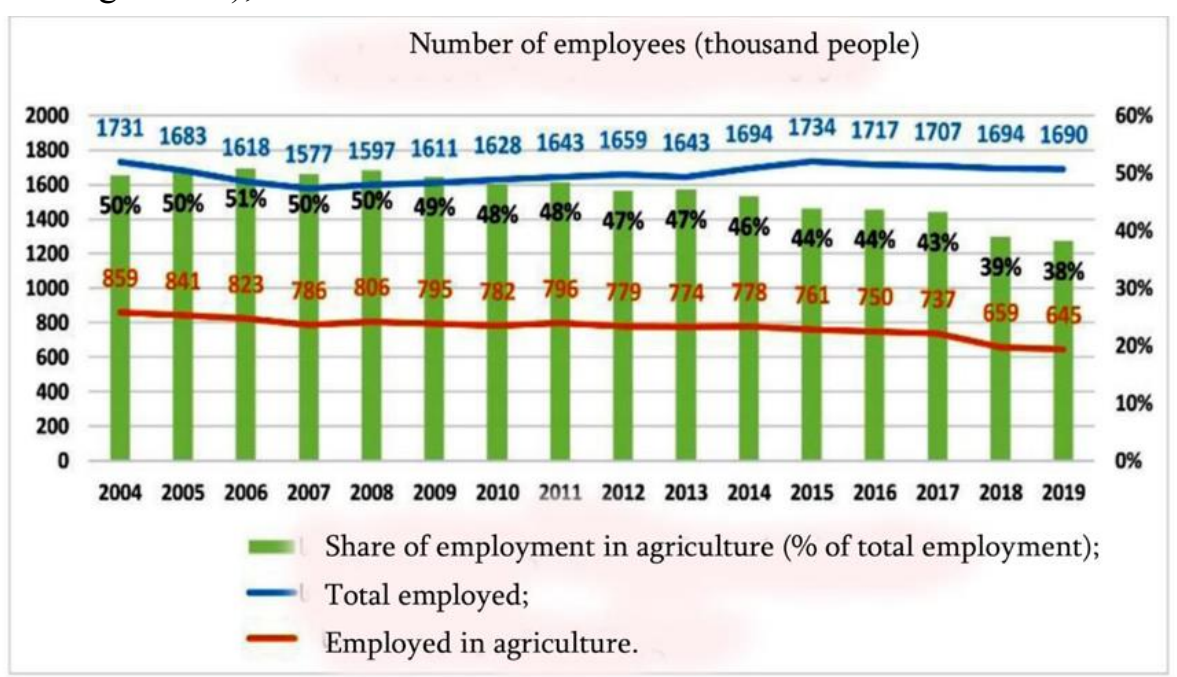

Fig. 3. Number (thousand people) of employees in the country in agriculture sphere Source: Data of National Statistics Office of Georgia-GEOSTAT

The need to switch from a linear economy to a circular economy.

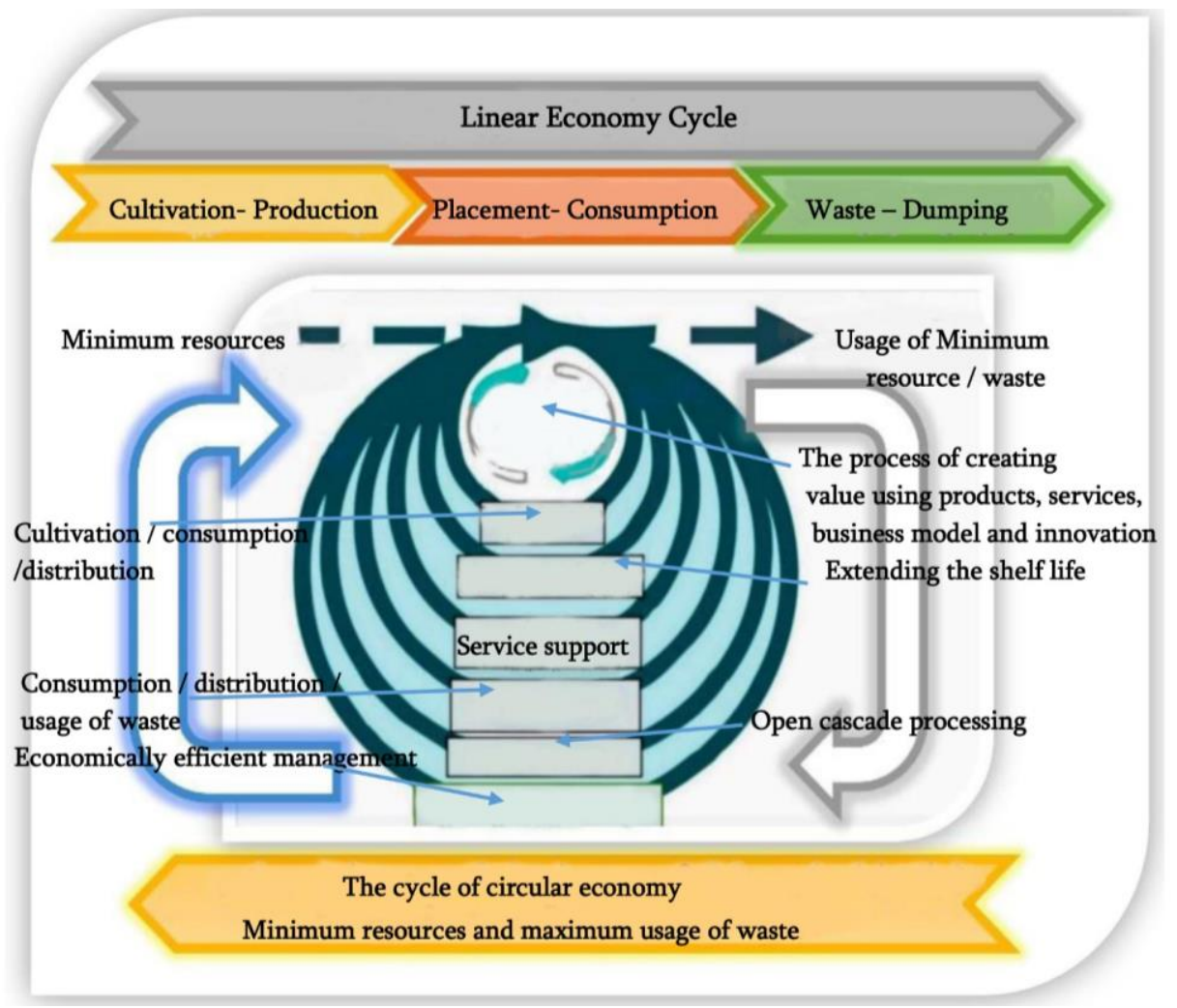

Fig. 4. Scheme of business opportunities of linear economy and circular economy in agriculture 


\section{Key Challenges.}

- Green growth and sustainable development are one of the major challenges in today's world;

- Today's agriculture is adapted to a linear economic model;

- The financial risk assessment of markets is built on a linear economy. External factors and existing challenges are not taken into account;

- The modern development requirements and move to the next level, which are precondition for maintaining sustainability, must be taken into account;

- The current economic system, the so-called the linear economy operates on the principle "take-consume-throw away" and consumes resources inefficiently.

- The resource scarcity and environmental pollution problems are becoming more acute day by day and the efficient management of limited resources and waste reduction is a significant challenge.

Effective management of agricultural business activities and shift to a circular economy, in particular, the development of concepts and business models relevant to market requirements is an alternative way to the promising development of the agricultural sector and increase the share of agriculture in the country's economy.

Circular Economy Business Opportunities. With effective economic management, when the organizations shift to a circular economy model, they become more sustainable and competitive:

- by identifying and effectively managing current and future impacts, risks and opportunities on the economy, which increases their viability, prevents environmental damage and provides social benefits;

- through the full application of resources and, at the same time, the reducing waste to the minimum (e.g., unused and / or unnecessary raw materials are returned for productive use); value chain;

- by strengthening relationships that can be achieved through effective collaboration with the

- building trust and credibility, which requires increased accountability and transparency;

- using the principles of circular economy as a general scheme for increasing or completely changing consumer value, which is achieved by stimulating learning and innovation and allows the organization to shift to more circular and sustainable activities if this is appropriate.

Analysis and Discussion of Results. The experience of European countries has shown that the organizations' economically effective management has been influenced by the linear economic approaches, schemes and regulations prevailing between production and consumption, because:

- assessment of markets, investment instruments and practices, including financial risk, are adapted to linear models;

- today's production is adapted to linear economic models;

- external factors and existing challenges related to linear business models are not taken into account.

The modern development requirements and move to the next level, which are prerequisite of maintaining sustainability for development must therefore be taken into account. Herewith, we should consider that green economic growth is one of the major challenges facing the world today.

Currently dominant economic system, the so-called the linear economy operates on the principle "take-consume-throw away" and consumes resources inefficiently. As a result, the resource scarcity and environmental pollution problems are becoming more acute day by day and the efficient management of limited resources and waste reduction is a significant challenge.

Circular economy is an alternative to traditional, linear economy, where we use resources as rationally as possible, spend the optimal amount of their value in use, and then, at the end of each cycle of operation, we restore products or raw materials and give them new life.

Sustainable development goals, optimization of resource use, major economic challenges, stakeholder engagement, the risk factors are the key issues to keep in mind when switching to a circular economy.

First of all, the enterprise should determine the expediency of the transition from the existing linear economic management system to the circular economy, the involvement of stakeholders, stages of the transition to circular economy, effective economic management of the enterprise, risks and opportunities.

Auxiliary models for circular economy should also be selected, the basic principles of waste management should be substantiated and prospects for the development of tomorrow's circular cities of enterprises.

The principles of economically effective management for Georgia and the stages of transition to a circular economy should be defined taking into account the UN Sustainable Development Goals 2030 and the preconditions for the transition to the circular economy. 
The attitude of the country towards the circular economy should be outlined and the steps to be taken and / or already taken in this direction should be established. The role of local government as a supportive and encouraging structure of the circular economy should be outlined and normatively established.

It is important to take the following measures during the sequential handling of these issues: reduction of the negative impact on the environment, processing and recycling the waste left after consumption.

\section{REFERENCES}

1. Pavliashvili S., Dr Dariusz Edward Prasek, Accelerating Transition to the Circular Economy in Georgia, "Moambe" Georgian Academy Press, vol.14, Tbilisi, 2020.

2. Pavliashvili S., Accelerating Georgia's Transition to a Circular Economy, Georgia Today, 1258, 2020

3. Pavliashvili S., The World Economic Crisis The Georgia, The Caucasus \& Clobalization, Volume 5, Isue 3-4. SWEDEN. 2011

4. Pavliashvili S., Zigzags of inflation in Post-Soviet Georgia, San-Fransisco, 2011.

5. Gubeladze D., Irrigation \& Drainage Systems of Georgia and Environmental Protection V International Scientific and Practical Conference "Modern Scientific Achievements and Their Practical Application", International Academy Journal, "Web of Scoular" October 31, Dubai, UAE, 2017.

6. Gubeladze D., Priorities for Agriculture Support Services in the Irrigation and Drainage Areas in Georgia IV International Scientific and Practical Conference "Topical Problems of Modern Science and Possible Solutions" International Scientific and Practical Conference "WORLD SCIENCE" 10(26), Vol.1, October 2017 Multidisciplinary Scientific Edition RS Global IV Dubai, 2017. 